NOTICE: this is the author's version of a work that was accepted for publication in Construction and Building Materials. Changes resulting from the publishing process, such as peer review, editing, corrections, structural formatting, and other quality control mechanisms may not be reflected in this document. Changes may have been made to this work since it was submitted for publication. A definitive version was subsequently published in Construction and Building Materials, Vol. 43 (2013)DOI:

10.1016/j.conbuildmat.2013.01.026 


\section{Review of Mechanical Properties of Short Fibre Reinforced Geopolymer Composites}

\section{Faiz Uddin Ahmed, Shaikh}

Department of civil engineering, Curtin University, Perth, Australia.

Abstract: Concrete exhibits brittle behaviour due to its low tensile strength. The addition of fibres, either short or continuous, changes its brittle behaviour to ductile or quasi-ductile with significant improvement in tensile strength, tensile strain, toughness and energy absorption capacities. The binder in the fibre reinforced cement composites (FRCC) is mainly Portland cement. The recent environmental awareness in construction industry promotes the use of alternative binders to partially or fully replace the cement as its production creates environmental pollution due to release of $\mathrm{CO}_{2}$ into atmosphere. Recent years have seen a great development in new types of inorganic cementitious binders called "geopolymeric cement” around the world. This prompted its use in concrete, which improves the greenness of ordinary concrete. Efforts have been made to replace the cement based binder in the current FRCC with "geopolymeric" binder resulting in fibre reinforced geopolymer composites (FRGC), which is greener than the former one. The development of FRGC is relatively new in the field of construction materials. This paper presents the state-of-the-art development of short fibre reinforced FRGC and its mechanical properties with emphasis on compressive strength, tensile strength, flexural strength, impact strength and toughness capacities. The durability properties of FRGC are also discussed in this paper. The recent development on ductile fibre reinforced geopolymer composites (DFRGC) exhibiting deflection hardening and multiple cracking behaviour in flexure is also presented here.

Keywords: Fibres, Mechanical properties, Geopolymer, composite. 


\section{Introduction:}

Concrete is the most widely used construction materials in the world. However, it exhibits poor tensile and flexural properties. One way to overcome this deficiency is the incorporation of fibres in concrete, resulting in fibre reinforced cementitious composites (FRCC). The addition of fibres improves its tensile and flexural strength, toughness and energy absorption capacities through bridging the cracks. The fibres in the FRCC, during loading, bridge the cracks and improve the toughness and reduce the crack width. The durability of FRCC is also enhanced through the crack control due to the presence of fibres. However, the current FRCCs are mostly manufactured by cement rich binder with limited use of supplementary cementitious materials (SCM) as partial replacement of cement [1-2].

The need for environmentally friendly construction materials for sustainable development is an important environmental issue at present time in the construction industry. The concrete industry is said to be one of the contributors of global warming. This fact is due to the use of Portland cement as the main component in the production of concrete and other cement based construction materials. The cement industry is responsible for about $6 \%$ of the $\mathrm{CO}_{2}$ emission worldwide. However, the use of concrete and cement based composites, as the most widely used construction materials, are still unavoidable in the foreseeable future. In this respect, the efforts of using SCM or finding alternatives to Portland cement are necessary. Recent years have seen a great development in new type of inorganic cementitious binder called "geopolymeric binder". This prompted its application in concrete, which improves the greenness of normal concrete and at the same time maintains comparable and even better properties [3].

It has been estimated that the manufacture of geopolymeric cement emits about $80 \%$ less $\mathrm{CO}_{2}$ than the manufacture of OPC [4-5], primarily because the limestone does not need to be calcined to produce the geopolymeric binder. Fly ash based geopolymers have 
extremely low embodied energies. In a geopolymer-based concrete (produced from fly ash and a soluble silica-like activator, and cured under mild heating), Tempest et al. [6] estimated that $70 \%$ less energy is consumed when compared with OPC-based concrete of similar strength. It has also been noted that sodium hydroxide $(\mathrm{NaOH})$ is a secondary product of the industrial process that produces chlorine; to assign $\mathrm{NaOH}$ the energy/ $\mathrm{CO}_{2}$ burden of the entire process is not entirely appropriate, as it is not the only product [5].

While considerable developments have been done on the geopolymer concretes, efforts have also been made to replace the cement based binder in the current FRCC with "geopolymeric binder" resulting in fibre reinforced geopolymer composites (FRGC). Although a great deal of important research has been performed in fibre reinforced geopolymer composites, the field is still relatively young. This paper presents the mechanical and durability properties of FRGC with emphasis on compressive, tensile, flexural and impact strength, toughness and energy absorption capacities. The effect of blending of different source materials used in the geopolymerisation, types of fibres and hybridisation of fibres on the above properties of FRGC is also discussed. The recent development on ductile fibre reinforced geopolymer composites (DFRGC) exhibiting deflection hardening and multiple cracking behaviour in flexure is also presented here.

\section{Source materials used in geopolymer:}

Geopolymers are amorphous three-dimensional alumina-silicate binder materials which are first named and developed by Davidovits in the late 1970s [7]. They are a member of the family of inorganic polymers and a chain structure formed on a backbone of aluminium (Al) and silicon (Si) ions. Geopolymers can be synthesized by mixing aluminasilicate reactive materials with strong alkaline solutions. Any material that is rich in Si and Al in amorphous form can be a possible source material for geopolymer binder. Several mineral and industrial by-products have been used in the production of geopolymer composites. They 
are metakaolin or calcined kaolin, fly ash, slag, natural alumina-silicate minerals, etc. Metakaolin is preferred due to its high rate of dissolution in the reactant solution, easier control on the $\mathrm{Si} / \mathrm{Al}$ ratio and the white colour. However, the high cost of metakaolin prohibits its mass use in the geopolymer matrices. Low calcium fly ash (ASTM class F fly ash) is the preferred source material than high calcium fly ash (ASTM class C fly ash). The presence of high amount of calcium in high calcium fly ash interfere the polymerisation process and alters the microstructure [8]. Natural alumina-silicate minerals have shown the potential source materials for geopolymerisation, although quantitative prediction on the suitability of specific mineral as the source material is still not available, due to the complexity of reaction mechanisms involved [9]. Among the by-product materials, fly ash and slag are the potential source materials for geopolymers. Fly ash is considered to be advantageous due to its high reactivity that comes from its finer particle size than slag. Moreover, low-calcium fly ash is more desirable than slag for geopolymer source material. Research shows that to produce optimal binding properties, the low-calcium fly ash should have the percentage of unburned material (LOI) less than $5 \%, \mathrm{Fe}_{2} \mathrm{O}_{3}$ content should not exceed $10 \%$, and low $\mathrm{CaO}$ content, the content of reactive silica should be between $40-50 \%$, and $80-90 \%$ of particles should be smaller than $45 \mu \mathrm{m}$. On the contrary, van Jaarsveld et al. [10] found that the fly ash with higher amount of $\mathrm{CaO}$ produced higher compressive strength, due to the formation of calcium-aluminate-hydrate and other calcium compounds, especially in the early ages. The other characteristics that influenced the suitability of fly ash to be a source material for geopolymers are the particle size, amorphous content, as well as morphology and the origin of fly ash.

\section{Alkaline solutions}

Alkaline solutions are also required to activate the source materials in the geopolymerisation process. The most common alkali activator used is combination of sodium 
silicate $\left(\mathrm{Na}_{2} \mathrm{SiO}_{3}\right)$ or potassium silicate $\left(\mathrm{K}_{2} \mathrm{SiO}_{3}\right)$ and sodium hydroxide $(\mathrm{NaOH})$ or potassium hydroxide $(\mathrm{KOH})$. Single alkali activator can also be used in the geopolymeric composites. Types of activator play an important role in the polymerisation process. Reactions occur at a high rate when the alkali activator contains soluble silicate compared to the only use of alkaline hydroxides.

\section{Manufacturing of fibre reinforced geopolymer composites (FRGC):}

The mixing and production of short fibre reinforced FRGC is similar to that of cement based system. The mixer used for conventional concrete or FRCC is also used to manufacture the FRGC. Generally, the source materials and fine aggregates (if used in certain amount) are first mixed in dry state in a standard pan or Hobart mixer for few minutes. The alkali activators and water (if needed) are then poured into the mixer and the mixing is continued for another few minutes. In some cases, superplasticizers are also used to improve the workability of the geopolymer matrix. The fibres are then added slowly to the geopolymer matrix and continue mixing until its uniform dispersion is observed in the mix. The freshly mixed FRGC is then cast in moulds. The premixing of sodium hydroxide powders with deionized water at least 24 hours before its use is recommended.

Unlike the cement based FRCC, the curing of FRGC requires slightly higher temperature than the ambient temperature for polymerisation process to continue. A wide range of temperatures and curing periods are used, ranging from room temperature up to about $90^{\circ} \mathrm{C}$ and from 1 hour to more than 24 hours. Metakaolin based geopolymers can be cured at room temperature for short period of time [7]. However, curing temperature and time played important roles on the properties of geopolymer materials made from by-product materials such as fly ash. Generally, in fly ash based geopolymer composites curing temperature of about $60^{\circ} \mathrm{C}$ is recommended [11]. 


\section{Mechanical properties of FRGC:}

\section{Compressive strength:}

Generally, geoplymer concrete exhibits higher compressive strength than that of OPC concrete [3]. However, conflicting results on the compressive strength of FRGCs are reported in the literature. In a recent study, Bernal et al. [12] reported reduction in compressive strengths of steel fibre reinforced slag based FRGC. They reported about 25\% and 23\% reduction of compressive strength at 7 and 28 days, respectively for FRGC containing $40 \mathrm{Kg} / \mathrm{m}^{3}$ steel fibres compared to unreinforced FRGC. The increase in steel fibre content from $40 \mathrm{~kg} / \mathrm{m}^{3}$ to $120 \mathrm{~kg} / \mathrm{m}^{3}$, however, didn't increase the compressive strength. Quite different results are observed in the FRCC using the same steel fibres in their study. Negligible reduction in compressive strength of FRCC containing $40 \mathrm{Kg} / \mathrm{m}^{3}$ steel fibres compared to unreinforced FRCC is observed at both ages (7 and 28 days). However, a big drop as high as $20 \%$ and $15 \%$ in compressive strength values at 7 and 28 days, respectively is observed when steel fibre content is increased from $40 \mathrm{~kg} / \mathrm{m}^{3}$ to $120 \mathrm{~kg} / \mathrm{m}^{3}$ in FRCC.

In another study on polypropylene (PP) fibre reinforced FRGC no such reduction in compressive strength is observed by Puertas et al. [13]. In their study, three different types of source materials such as slag, fly ash and slag/fly ash combination are used. The PP fibres are used as $0.5 \%$ and $1 \%$ by volume of mortar. In slag based FRGC, the addition of $0.5 \%$ and $1 \%$ PP fibre didn’t affect the compressive strength at 2 and 28 days. However, in fly ash based FRGC the 2-day compressive strength is increased due to increase of PP fibre contents. An opposite trend is observed at 28 days in the same composite. In the case of combined slag/fly ash based FRGC, slight increase in compressive strength is noticed by increasing the PP fibres from $0.5 \%$ to $1.0 \%$ at both ages.

In another study the improvement in early age compressive strength of PP fibre reinforced FRGC is reported compared to unreinforced one [14]. The source material in that 
study was combination of fly ash and calcined kaolin with a ratio of 1:2. The increase in compressive strength by about $68 \%$ and $20 \%$ at 1 and 3 days, respectively is observed in FRGC containing $0.5 \%$ PP fibre (by wt.). However, beyond this fibre content the rate of increase of compressive strength decreased at both ages.

\section{Flexural strength:}

The main objective of incorporation of fibres in cement mortar or concrete is to enhance their flexural and tensile strengths and change the brittle failure to ductile mode. Like cement based fibre composite, the tensile and flexural strength of fibre reinforced geopolymer composites (FRGC) are also increased due to addition of fibres. Bernal et al. [12] reported the flexural strength of steel fibre reinforced FRGC tested at 7, 14 and 28 days. In their study, the increase in flexural strength at all ages is observed. They also reported an increase in flexural strength with increase in curing time of all fibre contents. They observed as high as $70 \%$ increase in flexural strength of FRGC at 28 days. Bernal et al. [12] also measured the splitting tensile strength of the same composites and reported similar trend to flexural strength. It can be seen that the addition of steel fibres to the geopolymer matrix effectively improves the post cracking behaviour.

Recently, Zhang et al. [14] studied the early age flexural strength of PP fibre reinforced FRGC. Significant improvement in the flexural strength of PP fibre FRGC at 1 and 3 days are observed in their study. The flexural strength is doubled due to the addition of 0.75\% PP fibre at both ages. Surprisingly, the flexural strength is not improved in PP fibre FRGC [13]. The inferior performance in the above study could be attributed to the poor workability due to the addition of fibres in the geopolymer matrix.

In another study, Natali et al. [15] studied the flexural behaviour of metakaolin/slag based FRGC containing four different types of fibres. The fibres used in their study are carbon, E-glass, polyvinyl alcohol (PVA) and polyvinyl chloride (PVC). All fibres exhibited 
improvement in flexural strength of FRGC. Most notable carbon and PVA fibre reinforced FRGC exhibited about 50\% and 62\% increase in the flexural strength, respectively along with significant improvement in post-crack ductility as it can be seen from the wider curve branch in Fig. 1. The carbon FRGC also exhibited the highest toughness index among all FRGC.

The flexural behaviour of extruded PVA fibre FRGC made from a sodium silicate/sodium hydroxide activated metakaolin and fly ash/metakaolin blend is also reported [16-17]. The PVA fibres (14 $\mu \mathrm{m}$ in diameter, $6 \mathrm{~mm}$ in length) are used at $0 \%, 1 \%$, and $2 \%$ (by vol.) in the composite and the composite is produced using a single-screw extruder. The samples were allowed to cure at room temperature and flexural strength is measured after 28 days. In the flexural tests, the metakaolin based FRGC exhibited substantial increases in midpoint deflection and distributed micro-cracking due to increase in fibre content. However, the ultimate flexural strength is not improved due to the addition of PVA fibres in the metakaolin based FRGC. On the other hand, increasing the quantity of fly ash in metakaolin/fly ash blended FRGC decreases the flexural strength except the composite containing $10 \%$ fly ash, where the flexural strength is increased by about $30 \%$ than that containing no fly ash (i.e. 100\% metakaolin). The decrease in flexural strength could be due to less reactivity of fly ash than the metakaolin and 'dilutes' the strength-bearing phases. This is also observed during analysis of the failure mechanism, which varied from fibre fracture (low fly ash) to fibre pull out (high fly ash), as the weakening of the matrix due to reduced geopolymer formation which altered the fibre/matrix bonding. In this system, fly ash played a complex role in the metakaolin/fly ash blended geopolymeric composites [17].

\section{Impact strength:}

While considerable results are available on the compressive and flexural strength of FRGC, relatively little results are available on the impact behaviour of this material. Zhang et al. [18-19] studied the impact properties of the same extruded PVA fibre FRGC. In their 
study, plate specimens with the dimension of 75X90X6 mm are prepared for impact tests on an impact tester ITR-200, RADMANA. The effect of PVA fibre contents and fly ash contents on the impact properties of metakaolin based FRGC are also studied in that study. Figs. 2 and 3 show the impact behaviour of metakaolon based FRGC extruded plates with different volume fractions of PVA fibres and different percentages of fly ash, respectively. It can be seen that the geopolymer mortar (without fibre) has the highest impact strength of about $450 \mathrm{~N}$, while the impact displacement is very small only around $0.84 \mathrm{~mm}$. It can be seen that after peak load, the geopolymer mortar specimen cannot sustain any loading, resulting in a sharp drop of its impact curve. This indicates that the unreinforced geopolymer matrix will be broken without any warning when the peak load is reached leading to brittle failure.

When PVA fibres are incorporated and increased to 2\% (by Vol.) the impact behaviour of FRGC changed from brittle to ductile response after the peak load and exhibited strain hardening behaviour. The figure shows that the FRGC containing 2\% PVA fibre can sustain the peak load (429.6 N) up to around $2.5 \mathrm{~mm}$ of displacement. After that the bearing capacity falls slowly up to $7.5 \mathrm{~mm}$ of displacement. Fig. 4 shows the broken photo of $2 \%$ PVA fibre reinforced FRGC specimen after impact test. No crack is found on the surface of that specimen, only a hole caused by the high speed impact of the punch. The effects of fly ash contents on the impact behaviour of $2 \%$ PVA fibre reinforced FRGC is shown in Fig. 3. The impact test results are also shown in Table 1. As can be seen in Fig. 3 and Table 1, the impact resistance is a function of the percentages of fly ash. When $10 \%$ fly ash (by wt.) is added, not only are the impact strength and stiffness enhanced, but also is the toughness (absorbed energy) increased from $1833 \mathrm{~mJ}$ to $2108 \mathrm{~mJ}$. When too much fly ash are incorporated into geopolymeric mixture (30\% and 50\%), the impact resistance of FRGC is reduced rapidly, and the reduction rate is increased with an increase in the percentages of fly ash. It is especially true for $50 \%$ fly ash addition. For instance, when comparing with FRGC 
without fly ash the impact strength, stiffness and toughness of FRGC containing 50\% fly ash are reduced by $37.4 \%, 39.1 \%$ and $28.7 \%$, respectively.

The impact properties of FRGC were also the focus of research by $\mathrm{Li}$ and $\mathrm{Xu}$ [20-21]. In their study, the FRGC contained upto $0.3 \%$ basalt fibres and geopolymer matrix consisted of blended fly ash/slag and sodium silicate solution. Tests using a Split Hopkinson Pressure Bar (SHPB) system revealed no change in dynamic compressive strength, but improvements in deformation characteristics and a marked increase in energy absorption were observed. The fibre volume fraction of $0.3 \%$ was estimated to be the optimal fibre loading based on energy absorption.

\section{Fracture toughness:}

The fibres in cement based materials provide a control of cracking and increase the fracture toughness of brittle matrix through bridging action during both micro and macro cracking of the matrix. Very few results concerning the fracture behaviour of FRGC exists in the scientific literature [22-23]. Dias and Thaumaturgo [22] reported the fracture toughness of basalt fibre reinforced FRGC. In their study, metakaolin based geopolymer concrete is reinforced with $0.5 \%$ and $1.0 \%$ (by vol.) basalt fibre. The FRGC containing $0.5 \%$ and $1 \%$ basalt fibre exhibited approximately $14 \%$ and $111 \%$ increase in fracture toughness, respectively than that of cement composites. The results also show that the basalt fibres are more efficient in strengthening and toughening geopolymer concrete than ordinary concrete. It could be attributed to the better bond between fibre and geopolymer matrix. In another study, Silva and Thaumaturgo [23] also confirmed higher fracture toughness of FRGC than its cement based counterpart. In that study, the authors measured the fracture toughness of wollastonite micro fibre reinforced geopolymer mortar and reported higher values then those of cement based counterpart for the same fibre content. The better reinforcing efficiency observed in the geopolymer composite could be related to the nature of bond between fibre 
and matrix. The deboning and pullout of wollastonite micro fibre is the main toughening mechanisms in geopolymer composite as confirmed by the microstructure analysis in that study (Fig. 5 [23]).

\section{Deflection hardening behaviour:}

While the FRGC composites exhibited improved mechanical properties no study is reported to date on the deflection hardening and multiple cracking behaviour of this new material. The author, recently developed fly ash based FRGC containing steel and PVA fibres that exhibit deflection hardening and multiple cracking behaviour in bending. The newly developed composite is termed as ductile fibre reinforced geopolymer composites (DFRGC) which is analogous to its cement based counterpart the DFRCC (ductile fibre reinforced geopolymer composites) [24]. In this study the class F fly ash is used as the only source material for geopolymerisation and is activated by combined sodium silicate and sodium hydroxide solutions. Three types of fibres (steel and two types of PVA fibres) are considered in the study. The steel fibre is $10 \mathrm{~mm}$ long, whereas the PVA fibres are of two different lengths. One type of PVA fibre is 8mm long and termed as "PVA-1" and the other type is $12 \mathrm{~mm}$ long and termed as "PVA-2". Both are of different diameters, strengths and modulus. The fibres are used in mono as well as in hybrid combinations. The properties of fibres and chemical composition of fly ash used in this study are shown in Tables 2 and 3, respectively. The experimental program is divided into two parts. In the first part (Part A), cement based DFRCC containing steel and PVA fibres in mono and hybrid forms are considered. The second part (Part B), the geopolymer based DFRGC series, is similar to the first part in every aspect, except the matrix where the cement is replaced by the class F fly ash and is activated by the alkaline activators (Sodium hydroxide and sodium silicate). The total volume fraction of fibres is limited to $2 \%$ for all fibre types and hybrid combinations of steel-PVA fibres. In each part, five series are considered. Detail experimental program is shown in Table 4. Series 
1 and 6 is designed to compare the deflection hardening behaviour of mono fibre reinforced DFRGC with that of its cement based counterpart, DFRCC. The rest of the series in both parts are designed to evaluate the effect of hybrid combinations of steel-PVA fibres on the deflection hardening behaviour of DFRGC composites having different sand sizes and sand/binder ratios and compared with those of FRCC. For each series, three prismatic specimens of 20X75X300 mm in dimension are cast. All specimens are tested in four-point bending using an Instron testing machine under displacement control with a loading rate of $0.5 \mathrm{~mm} / \mathrm{min}$.

Fig. 6 shows the deflection hardening behaviour of both cement based and geopolymer based mono fibre reinforced composites (i.e. the DFRCC and DFRGC) in bending and the comparison between the two can also be seen in the same figure. Generally, the composite containing $2 \%$ steel fibre exhibited much higher flexural strength than those containing PVA-1 and PVA-2 fibres of same volume fraction. But its deflection capacity (deflection at peak load) is much lower than that containing PVA-2 fibre. However, its deflection capacity is comparable to that containing PVA-1 fibre. The higher flexural strength and smaller deflection capacity of steel fibre reinforced DFRCC and DFRGC compared to its counter parts PVA-1 and PVA-2 fibres systems is due to the high modulus of steel fibres. The lower flexural strength with considerable higher deflection capacity of PVA fibre reinforced composites is due to the low modulus of PVA fibres. Other researchers also observed similar behaviour in both steel and PVA fibre reinforced cement based composites (e.g. [2]). The geopolymer based DFRGC exhibited comparable deflection hardening behaviour in bending to that of cement based system with only exception with the composite containing PVA-2 fibre, where no deflection hardening behaviour is noticed. It should be noted that PVA-2 fibre is about 33\% longer and about 31\% weaker than that of PVA-1 fibre. Research suggests that if the length of fibre exceeds the critical fibre length, the fibres rupture 
rather than pull out in cement based composites [25]. Research also suggests that, in addition to friction bond, chemical bond also develops between PVA fibre and cement matrix [26]. Therefore, the poor behaviour observed in PVA-2 fibre reinforced FRGC could be attributed to the longer length and lower strength of PVA-2 fibre than that of PVA-1 fibre. In the case of DFRGC, the chemical bond might be higher than that of cement based matrix, which might adversely affected the deflection hardening behaviour of the composite containing PVA-2 fibre. But it is not in the case of DFRGC containing PVA-1 fibre, whose deflection capacity is higher than that of cement based system, which is still not clear and need to be thoroughly investigated through measuring the frictional bond of PVA fibres in the geopolymeric matrix.

The effect of geopolymeric matrix on the deflection hardening behaviour of hybrid steel-PVA fibre reinforced FRGC composites and its comparison with that of cement based DFRCC is shown in Figs. 7-10. Generally, the hybrid fibre reinforced DFRGC exhibited comparable deflection hardening behaviour and deflection at peak load to that of DFRCC. In this study, two hybrid combinations are considered, one with 1\% ST and 1\% PVA-1 fibres and the other with 1\% ST and 1\% PVA-2 fibres. The DFRGC containing the former hybrid combination exhibited better deflection hardening behaviour than that of DFRCC. In the case of second hybrid combination, the DFRGC exhibited similar deflection hardening behaviour to that of DFRCC. It is interesting to note that, by replacing 1\% PVA-2 fibre with ST fibre in 2\% PVA-2 fibre reinforced DFRGC (series 6), the deflection hardening behaviour can be reinstated, which was not observed in mono fibre system.

The effects of sand contents and its sizes on the deflection hardening behaviour of DFRCC and DFRGC can also be seen by comparing Figs. 7-10. It can be seen that, for a given sand/binder ratio (S/B), the increase in sand size (from $0.6 \mathrm{~mm}$ to $1.18 \mathrm{~mm}$ ) adversely affected the deflection hardening behaviour, where the flexural strength increased and the 
deflection at peak load decreased with increase in sand size. The DFRGC also exhibited similar trend to that of DFRCC in terms of deflection at peak load and deflection hardening behaviour. The effects of sand in the matrix of DFRCC and DFRGC on the deflection hardening behaviour are also shown in the above figures. The adverse effect of increasing the amount of sand on the deflection at peak load can be seen in both composites, which is also reported in other studies [27-28]. The DFRGC also exhibited comparable multiple cracking to that of DFRCC (compare Fig. 11 with Fig. 12)

\section{Durability properties of FRGC}

While considerable researches are conducted on the mechanical properties of FRGC, relatively less research is reported on the durability properties of this material. For a successful application in construction durability requirements also need to be satisfied together with mechanical properties. Puertas et al. [13] in their study evaluated the shrinkage behaviour and residual strength after freezing/thawing and wet/dry cycles of PP fibre reinforced FRGC composite. The shrinkage tests were carried out according to ASTM C 80687 [29] standard on 2.5X2.5X23 cm prism specimens. Among different source materials the fly ash based FRGC exhibited lowest shrinkage at all ages upto about 40 days under both humid ( $\mathrm{RH}>95 \%)$ and dry ( $\mathrm{RH}=50 \%$ in laboratory) conditions (see Fig. 13). The shrinkage results of all other FRGCs such as slag and combined slag/fly ash based as well as cement based FRCC is also shown in Figs. 14-16 for comparison. It can be seen that under controlled laboratory dry condition both slag and slag/fly ash based FRGC exhibited similar shrinkage to that of cement based FRCC. The better performance of fly ash based FRGC could be due to the stability of the main reaction product, a 3D structure formed by alumina-silicate hydrates [13]. The effect of cyclic wet/dry cycles on the impact behaviour of FRGC is also evaluated by the same authors. In their study the $16 \mathrm{X} 16 \mathrm{X} 2.5 \mathrm{~cm}$ prism specimens were subjected to 50 wet/dry cycles and impact strength is measured by dropping a 540 gms 
weight from $1 \mathrm{~m}$ height. Results show that, similar to shrinkage result, the fly ash based FRGC exhibited 200\% increase in number of impact required to create the first crack after 50 wet/dry cycles. The slag based system exhibited only 50\% increase in the number of impact required to create the first crack. The cement based FRCC, on the other hand, showed 50\% decrease in the number of impact required to create the first crack after 50 wet/dry cycles. The fly ash based FRGC also exhibited better behaviour in term of resistance against fracture after 50 wet/dry cycles than slag and combined slag/fly ash based system. The same author also studied the effect of freezing and thawing on the mechanical behaviour of these geopolymeric fibre composites. In this study, the slag based FRGC exhibited best performances among all geopolymeric fibre composites. It exhibited about $28 \%$ and $17 \%$ increase in flexural and compressive strengths, respectively after 50 freeze/thaw cycles. On the other hand, the fly ash based FRGC exhibited poor performance in terms of $41 \%$ and $20 \%$ reduction in flexural and compressive strengths, respectively after 50 freeze/thaw cycles. The cement based FRCC also exhibited reduction in flexural and compressive strengths after the freeze/thaw cycles.

The freeze-thaw durability of steel fibre reinforced geopolymer composites (steel FRGC) is also studied by Zhang et al. [19]. In their study, the steel FRGC extruded plate specimens were subjected to 20 freeze-thaw cycles followed by impact test. All composites contained $2 \%$ steel fibre with different percentages of fly ash ranging from $0 \%$ to $50 \%$. Fig. 16 shows the impact responses of various steel FRGCs after 20 cycles of freeze-thaw. No obvious change in the impact strength is seen for the steel FRGC with fly ash after 20 freeze-thaw cycles, compared to the same composite before freeze-thaw cycles (Fig. 17(cd)). However, the steel fibre FRGC without fly ash shows a quite different result than the composites with fly ash (Fig. 17(a)). The impact resistance of the composites without fly ash is not reduced, but an increase is found. The observation is not consistent with what is 
commonly observed in cement based system expect: the impact behaviour of hardened cementitious paste generally reduces after freeze-thaw cycles. The reason for this may be explained by the following facts: (1) The steel FRGC is so dense and compacted that water cannot penetrate inside the plates, resulting in almost no freeze-thaw deterioration. (2) Geopolymeric products might further formed during the long duration of freeze- thaw test. Based on the test results and analysis, the steel fibre FRGC exhibited excellent resistance to freeze-thaw cycles.

The resistance against acid is also studied for FRGC. Zhang et al. [19] reported some experimental results in terms of impact behaviour of steel FRGC extruded panels after subjected to sulphuric acid solution for about a month. Geopolymeric cement doesn't produce lime $(\mathrm{CaO})$ during hydration process, unlike conventional Portland cement, thus theoretically not dissolved in acidic solutions. Hence, the geopolymeric composite supposed to exhibit excellent acid resistance. However, still experimental investigations are required to evaluate the performance of fibre reinforced geopolymer composite and in particular the fibres in the composite. The impact response behaviour of various steel FRGCs is shown in Fig. 18(a-d) after subjected to $\mathrm{H}_{2} \mathrm{SO}_{4}$ solution. For comparison, the impact response curves of the corresponding composites before attack are also displayed in figure. It can be seen from the figures that after subjecting to acid attack the impact strength and stiffness of composite without fly ash are reduced by $4.5 \%$ and $11.8 \%$, respectively. However, the impact toughness increased by around $35.3 \%$. This improvement in toughness is assigned to the fact that there exists a platform with long displacement and high load resistance in impact response curve of that composite after acid attack, as shown in Fig. 18(a). The effects of fly ash on acid resistance of steel FRGC are shown in the same figure. As can be seen from these figures, the impact resistance of steel FRGC with various percentage of fly ash (10\%, 30\% and 50\% designated as FA10, FA30 and FA50, respectively in Fig. 18b, c and d) is not reduced after 
acid attack, but a considerable improvement, particularly for composite containing 30\% and $50 \%$ fly ash, which is quite different from that without fly ash is reported.

\section{Opportunities and challenges in FRGC}

The sustainability of cement based construction materials depends on two main factors: the materials greenness and the durability. The greenness of cement based materials again depends on the amount of virgin resources used in the system, the pollutants produced during manufacturing of cement and other cement based materials and the embodied energy of these materials from manufacturing to delivery. By reducing the use of virgin resources and releasing less pollutant into the atmosphere, maximising the use of other SCMs in lieu of cement and reducing the energy consumption in the manufacturing process the material greenness can be achieved. Durability dictates the minimum maintenance require during the life of a structure. Compared to other construction materials, such as steel and wood, the OPC concrete is extremely brittle and cracks under mechanical and environmental loading, which leads to the wide spread deterioration of structures. By improving the ductility and controlling the width of cracks in the concrete, the ultimate durability of concrete infrastructure can be enhanced significantly. One of the examples is the development of high performance fibre reinforced cementitious composites [1, 30-31]. New building materials that enhance both material greenness and durability could reduce long-term costs by reducing the costly repair and maintenance. Improvement of these two aspects of infrastructure materials will lead to system with enhanced sustainability. As mentioned at the beginning, the "geopolymeric binder" which utilises waste/by products, such as fly ash, slag, etc. and replaces cement satisfies most of the requirements for materials greenness. It also exhibits similar and/or superior mechanical and durability properties than concrete except the cracking under loads which can be addressed by using fibres [32]. 
The fibre reinforced geopolymer composites (FRGC) is relatively new branch in geopolymeric composites especially geopolymers reinforced by randomly distributed short fibres. Despite numerous researches on the mechanical and durability properties of FRGC, some challenges still exist and need to be addressed in order to exploit this new fibre composite material in infrastructure use. Some of the challenges are, i) The variability of quality and composition of source materials used in geopolymeric cement, such as fly ash, slag or others, make standardisation and comparison between research efforts more complicated; ii) The acceptance and familiarity of geopolymer composite is largely limited to academic and research circles; iii) The chemical process involves in geopolymerisation is complex and its understanding is still not mature; and iv) The lack of long term data on various mechanical and durability properties of this fibre composite is still limited; v) The lack of information on the interaction of fibres with geopolymer matrix and toughness of matrix itself.

Geopolymers are an alternative binder system fabricated predominantly from secondary products that are in ready supply worldwide; wide scale adoption, if practical, shows the promise to reduce the environmental impact when compared to conventional cement rich materials. The unique chemical structure of this class of materials leads to numerous superior properties that have been the subject of significant studies such as superior fire resistance, acid resistance, corrosion resistance, etc. However, if geopolymer composites with enhanced ductility and durability through fibre reinforcement can be developed, such materials will provide a significant improvement in durability of civil infrastructure systems in future.

\section{Conclusions:}

This paper presents state-of-the-art mechanical and durability properties of short fibre reinforced geopolymer composites. In most of the researches the fly ash, slag and metakaolin 
are used as source materials in the "geopolymeric" matrix either alone or in blended form and are activated through the use of sodium hydroxide/potassium hydroxide and/or sodium silicate/potassium silicate solutions. Different short fibres are also used to reinforce the geopolymer matrix. Based on limited available results on mechanical and durability properties of this new fibre composite the following conclusions can be made:

- No significant improvement in the compressive strength at early and late ages of slag based FRGC is observed despite use of different fibres such as steel and polypropylene fibres.

- Improvement in the compressive strength at early and late ages of fly ash and blended fly ash/metakaolin based FRGC is observed.

- Significant improvements in flexural and tensile strength of FRGC are observed at early ages up to 28 days regardless of fibre types and contents.

- In blended fly ash/metakaolin based FRGC containing PVA fibre the optimum fly ash content for improved flexural strength in FRGC is found to be 10\%. Any further increase in the fly ash content adversely affects the flexural strength.

- The fracture toughness of fibre reinforced geopolymer composites is higher than that of cement based system.

- No long term results on the above properties of FRGC are available. Thus more research need to be conducted in this area as the fibres might be affected in the FRGC due to use of alkaline solutions in this composite than its cement based counterpart.

- Significant improvement in impact behaviour of FRGC is reported by many researchers. The same is also true even after several cycles of wet/dry, freeze/thaw and even after immersed in acid solution.

- The fly ash based FRGC exhibited lower shrinkage than that of slag and fly ash/metakaolin based system. 
- The slag based FRGC exhibited improvement in compressive and flexural strengths after 50 cycles of wetting and drying. On the other hand, the fly ash based FRGC exhibited improvement in the above properties after 50 cycles of freezing and thawing.

- The recently developed fly ash based geopolymeric DFRGC exhibited deflection hardening and multiple cracking behaviour in bending.

- The observed deflection hardening and multiple cracking behaviour in bending is comparable to its cement based counterpart DFRCC.

- More research is needed in this area to translate the observed deflection hardening and multiple cracking behaviour from bending to strain hardening in uniaxial tension with significant increase in strain capacity.

- Once enhanced ductility with multiple micro cracks in this new composite is confirmed a new opportunity for better durability of this composite can be explored.

\section{Reference:}

1. Li, V.C., Wang, S. and $\mathrm{Wu}, \mathrm{C}$. (2001). Tensile strain-hardening behaviour of Polyvinyl Alcohol Engineered Cementitious Composites (PVA-ECC). ACI Materials Journal, Nov.-Dec. 2001, pp. 483-492.

2. Ahmed, S.F.U. Maalej, M. and Paramasivam, P. (2006). Flexural responses of hybrid steel-polyethylene fibre reinforced cement composites containing high volume fly ash. Journal of construction and building materials, 21: 1088-1097.

3. Rangan, B.V. (2007) Low calcium fly ash bsed geopolymer concrete. In: Nawy EG editor. Concrete construction engineering handbook. New York, CRC press.

4. Davidovits, J. (1994). Global warming impact on the cement and aggregates industries. World Resource Review, 6(2), 263-278. 
5. Duxson, P., Fernández-Jiménez, A., Provis, J. L., Lukey, G. C., Palomo, A., \& van Deventer, J. S. J. (2007). Geopolymer technology: The current state of the art. Journal of Material Science, 42, 2917-2933.

6. Tempest, B., Sanusi, O., Gergely, J., Ogunro, V., \& Weggel, D. (2009). Compressive strength and embodied energy optimization of fly ash based geopolymer concrete. Paper presented at the world of coal ash (WOCA) conference.

7. Davidovits, J. (1989). Geopolymers and geopolymeric new materials. Journal of thermal analysis, 35(2): 429-441.

8. van Deventer, J. S. J., Provis, J. L., Duxson, P., \& Lukey, G. C. (2007). Reaction mechanisms in the geopolymeric conversion of inorganic waste to useful products. Journal of Hazardous Materials, 139(3), 506-513.

9. Xu, H. and van Deventer, J.S.J., (2000).The geopolymerisation of alumino-silicate minerals. Int. J. Miner. Process., 59: 247-266.

10. van Jaarsveld, J.G.S. and van Deventer, J.S.J., (1999). Effect of the metal alkali activator on the properties of fly ash-based polymers. Ind. Eng. Chem. Res., 38: 39323941.

11. Shaikh, F.U.A., Lu, Y.Y. and Maalej, M. (2013) Development of ductile fibre reinforced geopolymer composites, Proceedings of eighth international conference on fracture mechanics of concrete and concrete structures, Spain. Van Mier et al. (eds).

12. Bernal, S., Gutierrez, R.D., Delvasto, S. and Rodriguez, E. (2010) Performance of an alkali-activated slag concrete reinforced with steel fibres. Construction and building materials, 24, 208-214.

13. Puertas, F., Amat, T., Fernandez-jimenez, A. and Vazquez, T. (2003) Mechanical and durable behaviour of alkaline cement mortars reinforced with polypropylene fibres, Cement and concrete research, 33, 2031-2036. 
14. Zhang, Z., Yao, X., Zhu, H. and Hua, S. (2009) Preparation and mechanical properties of polypropylene fibre reinforced calcined kaolin-fly ash based geopolymer , Journal of central southern university of Technology, 16, 49-52.

15. Natali, A., Manzi, S. and Bignozzi, M.C. (2011) Novel fibre reinforced composite materials based on sustainable geopolymer matrix, Procedia engineering, 21, 11241131.

16. Li, Z., Zhang, Y. and Zhou, X. (2005) Short fibre reinforced geopolymer composites manufactured by extrusion, Journal of materials in civil engineering, 17(6), 624-631.

17. Zhang, Y., Sun, W., Li, Z. and Zhou, X. (2009) Geopolymer extruded composites with incorporated fly ash and polyvinyl alcohol short fibre, ACI materials journal, 106(1), 3-10.

18. Zhang, Y., Sun, W. and Li, Z. (2006) Impact behaviour and microstructural characteristics of PVA fibre reinforced fly ash geopolymer boards prepared by extrusion technique, Journal of materials science, 41, 2787-2794.

19. Zhang, Y., Sun, W. and Li, Z., Eddie, and Chungkong, C. (2008)Impact properties of geopolymer based extrudates incorporated with fly ash and PVA short fibre, Construction and building materials, 22, 370-383.

20. Li, W. and Xu, J. (2009a) Mechanical properties of basalt fibre reinforced geopolymeric concrete under impact loading. Materials science and engineering A, 505, 178-180.

21. Li, W. and Xu, J. (2009b) Impact chacterization of basalt fibre reinforced geopolymer concrete using a 100mm diameter split Hopkinson pressure bar. Materials science and engineering A, 513-514, 145-153.

22. Dias, D.P. and Thaumaturgo, C. (2005) Fracture toughness of geopolymeric concretes reinforced with basalt fibres, Cement and concrete composites, 27: 49-54. 
23. Silva, F.J. and Thaumaturgo, C. (2003) Fibre reinforcement and fracture response in geopolymeric mortars, Fatigue fracture engineering materials structure, 26: 167-172.

24. JCI-DFRCC Committee, (2003) Technical report on the terminology, Journal of Advanced Concrete Technology, 1(3): 335-340.

25. Ahmed, S.F.U., Maalej, M. and Paramasivam, P. (2007). Analytical model for tensile strain hardening and multiple cracking behaviour of hybrid fiber engineered cementitious composites, Journal of materials in civil engineering, 19(7): 527-539.

26. Kanda, T. and Li, V.C. (1999), New micromechanics design theory for pseudo strain hardening cementitious composites, Journal of engineering mechanics, 125(4):373381.

27. Ahmed, S.F.U. and Mihashi, H. (2011), Strain hardening behaviour of lightweight hybrid polyvinyl alcohol (PVA) fiber reinforced cement composites, Materials and structures, Vol. 44, pp. 1179-1191.

28. 14. Akkaya, Y., Peled, A., Picka, J.D. and Shah, S.P. (2000) Effect of sand addition on properties of fiber reinforced cement composites, ACI materials journal, 97(3): $393-400$.

29. ASTM C806-87 Standard test method for restrained expansion of expansive cement mortar, ASTM international.

30. Naaman, A.E. and Reinhardt, H.W. (2006), Proposed classification of HPFRC composites on their tensile response, Materials and structures, Vol. 39, pp. 547-555.

31. Ahmed, S.F.U. and Maalej, M. (2009) Tensile strain hardening behaviour of hybrid steel-polyethylene fibre reinforced cementitious composites. Journal of Construction and Building Materials Vol. 23, No.1, pp.96-106.

32. Sakulich, A.R. (2011) Reinforced geopolymer composites for enhanced material greenness and durability, Sustainable cities and society, 1, 195-210. 


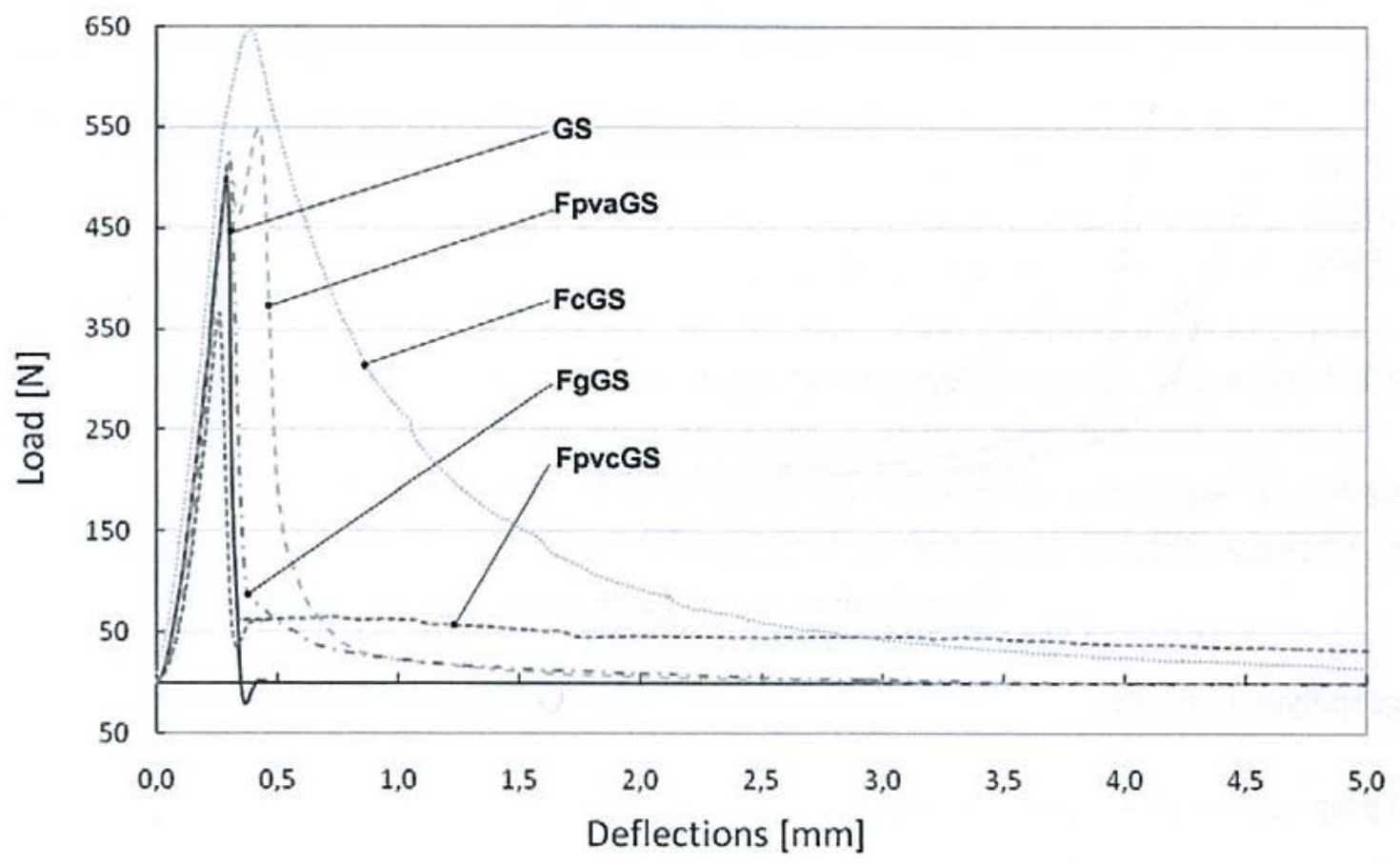

Fig. 1. Load-deflection behaviour of FRGC containing carbon, PVA, PVC and E-glass fibres. (Adopted from, [15])

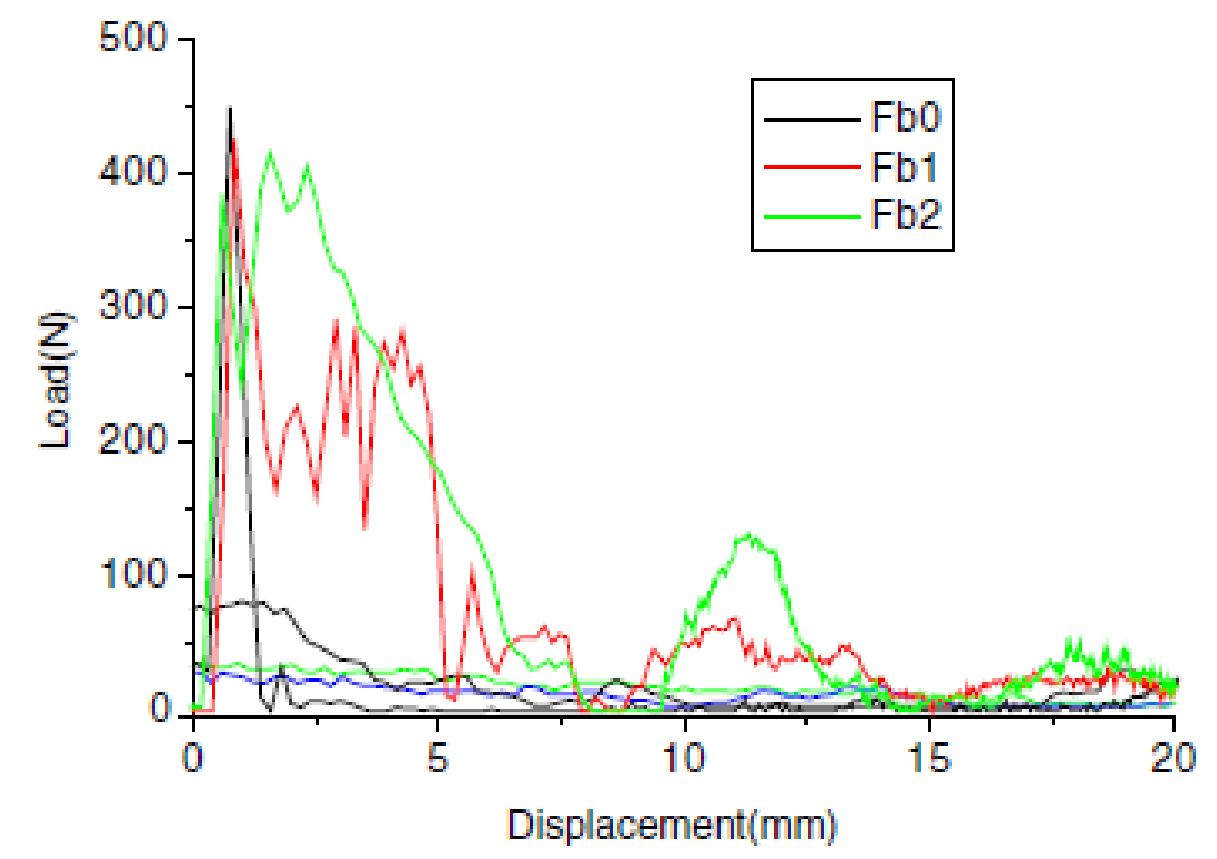

Fig. 2 Impact behaviour of metakaolin based FRGC containing PVA fibres of different volume fractions. (Note: Fb0 indicates 0\% PVA fibres, while Fb1 and Fb2 indicate 1\% and 2\% PVA fibre, respectively. (Adopted from, [19]) 


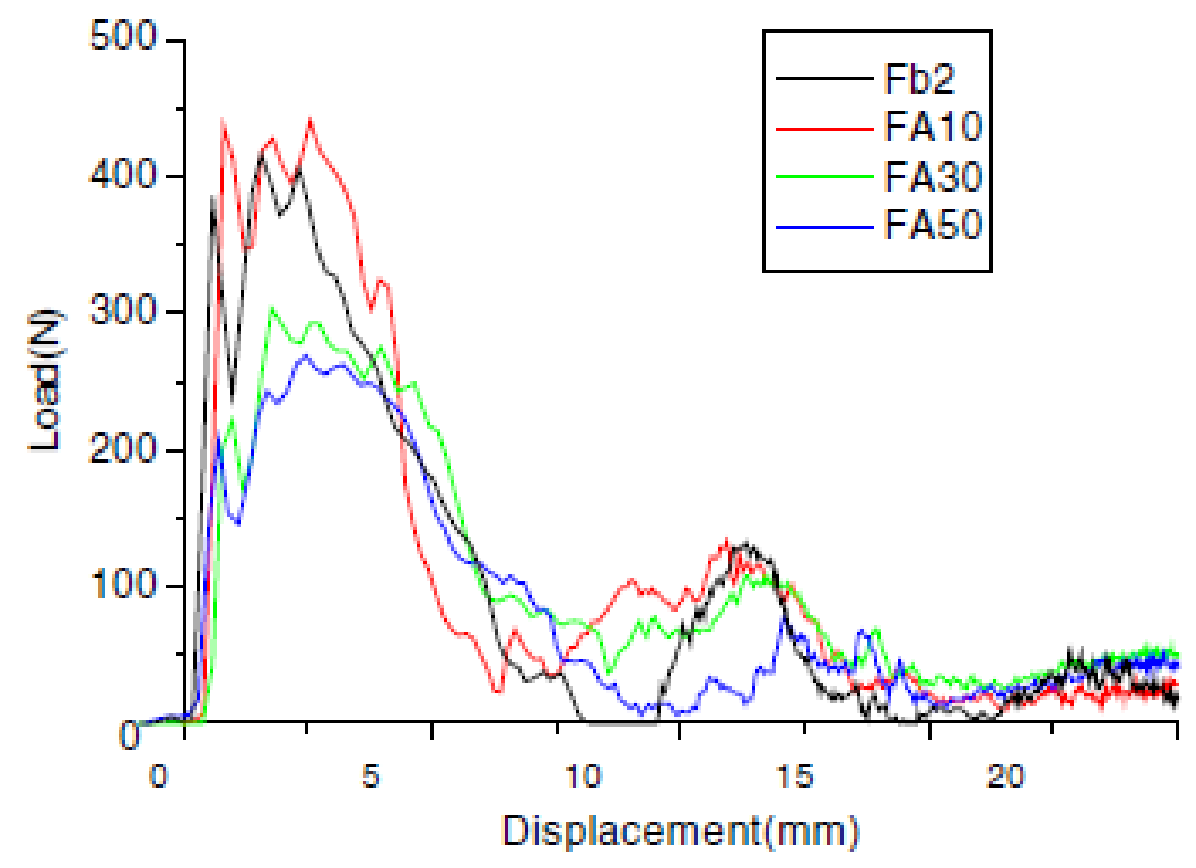

Fig. 3 Impact behaviour of 2\% PVA fibre reinforced and metakaolin based FRGC containing different percentages of fly ash. (Note: Fb2 indicates metakaolin based FRGC containing 2\% PVA fibres, while FA10, FA30 and FA50 indicate 10\%, 30\% and 50\% replacement of metakaolin with fly ash, respectively in Fb2 composite. (Adopted from, [19])

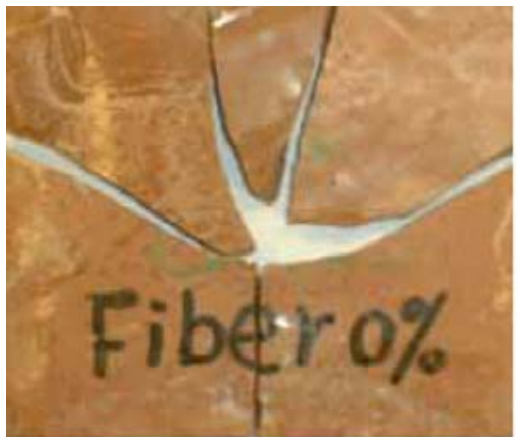

a

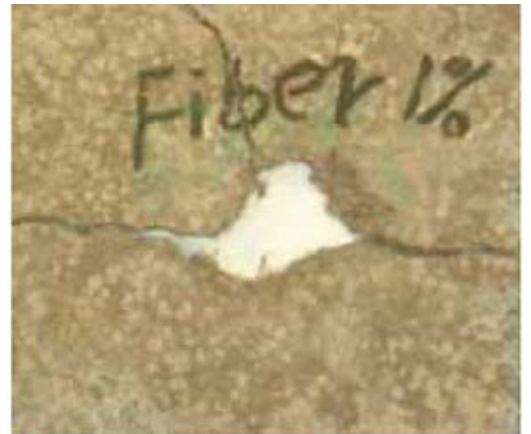

b

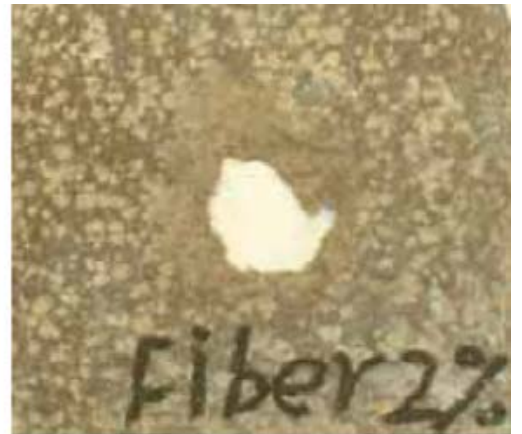

C

Fig. 4 Fractured images of metakalion based FRGC containing 0\% (a), 1\% (b) and 2\% (c) PVA fibres. (Adopted from, [19]) 


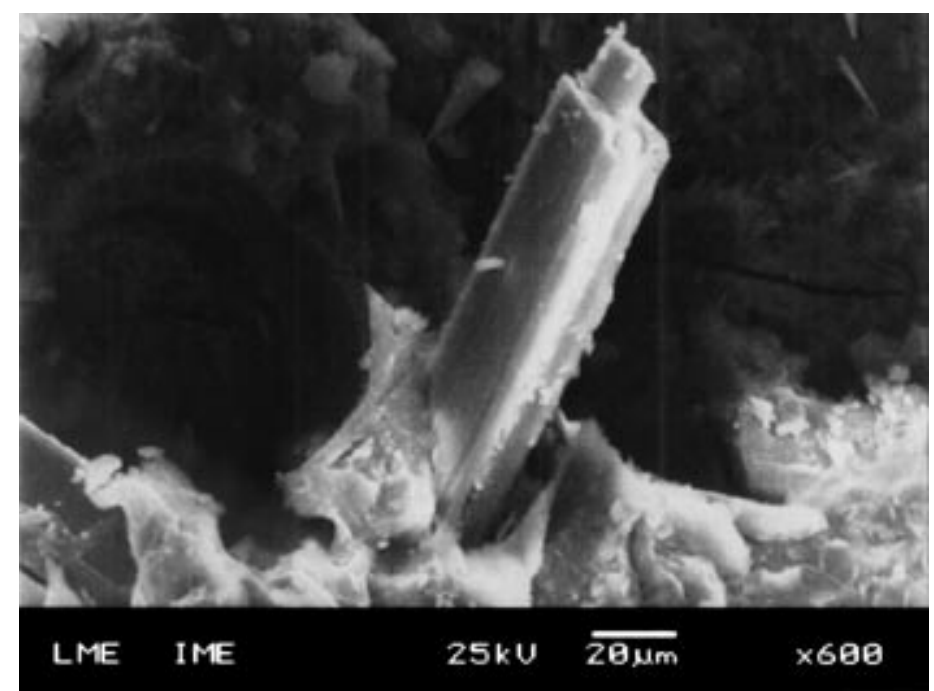

Fig. 5 SEM micrograph of geopolymer composite showing the pullout of wollastonite micro fibre [23]

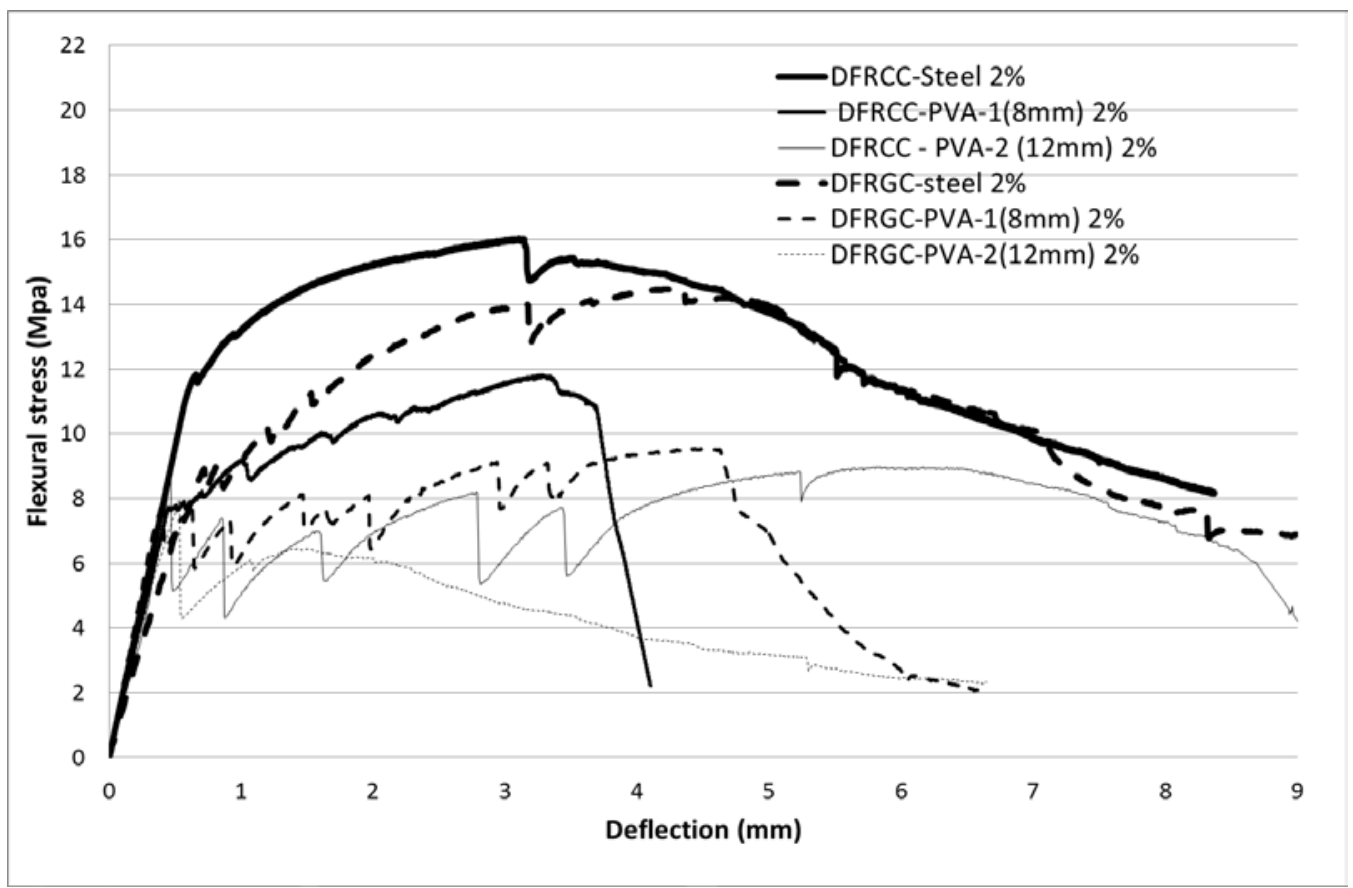

Fig. 6. Deflection hardening behaviour of mono fiber reinforced DFRCC and DFRGC in bending. 


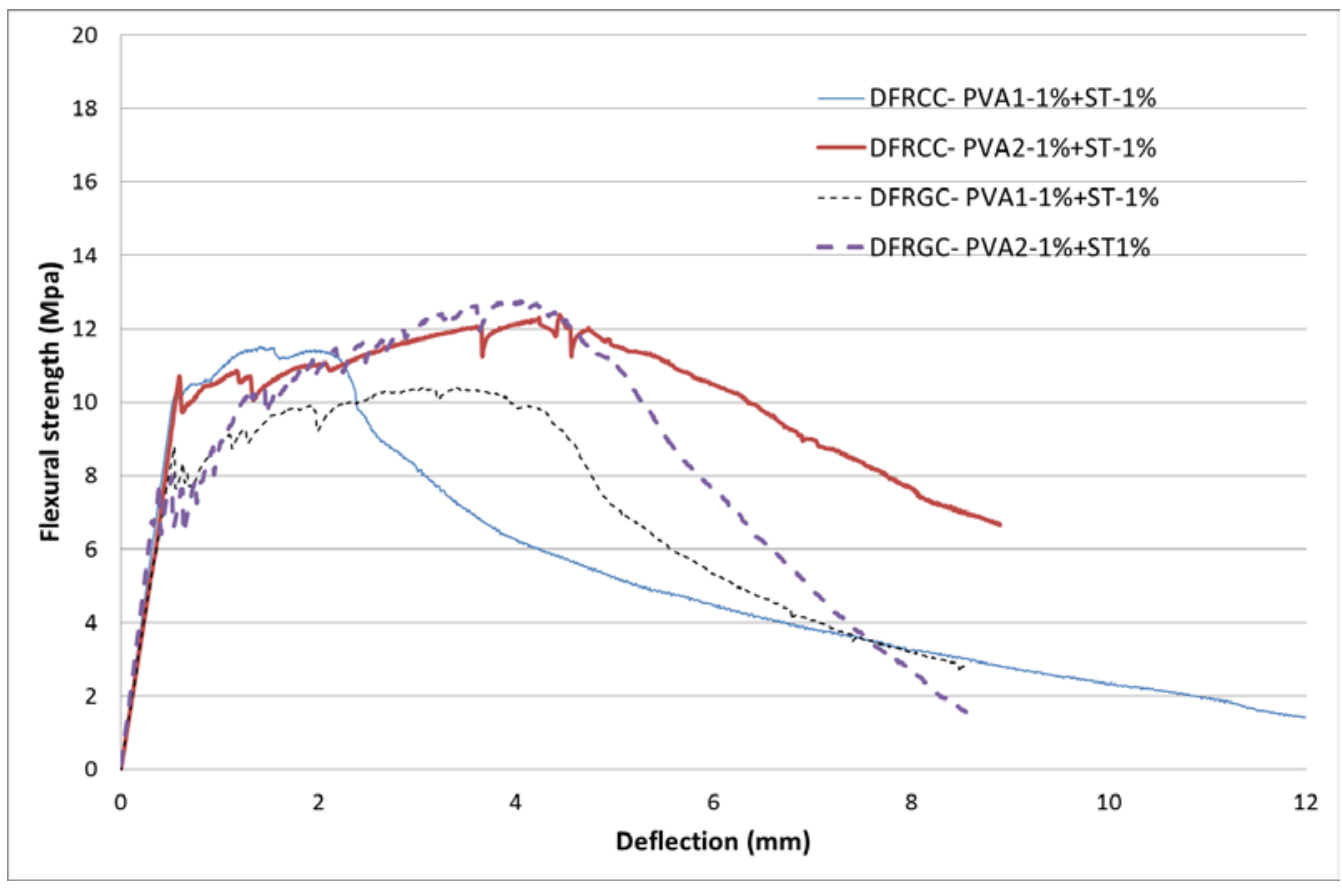

Fig. 7. Deflection hardening behaviour of hybrid fiber reinforced DFRCC and DFRGC in bending containing $\mathrm{S} / \mathrm{B}$ ratio of 0.5 and maximum sand size of $0.6 \mathrm{~mm}$

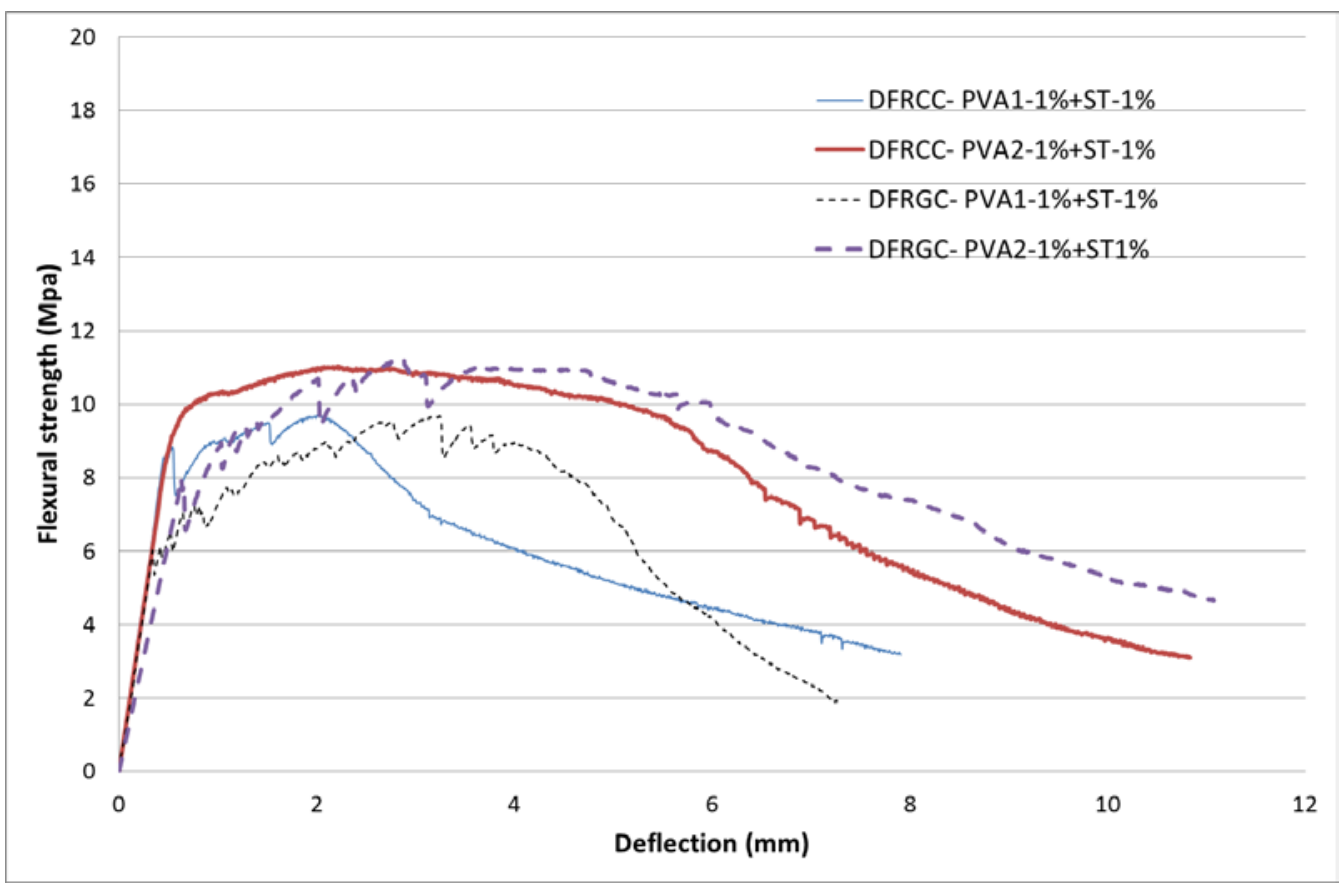

Fig. 8. Deflection hardening behaviour of hybrid fiber reinforced DFRCC and DFRGC in bending containing S/B ratio of 0.75 and maximum sand size of $0.6 \mathrm{~mm}$ 


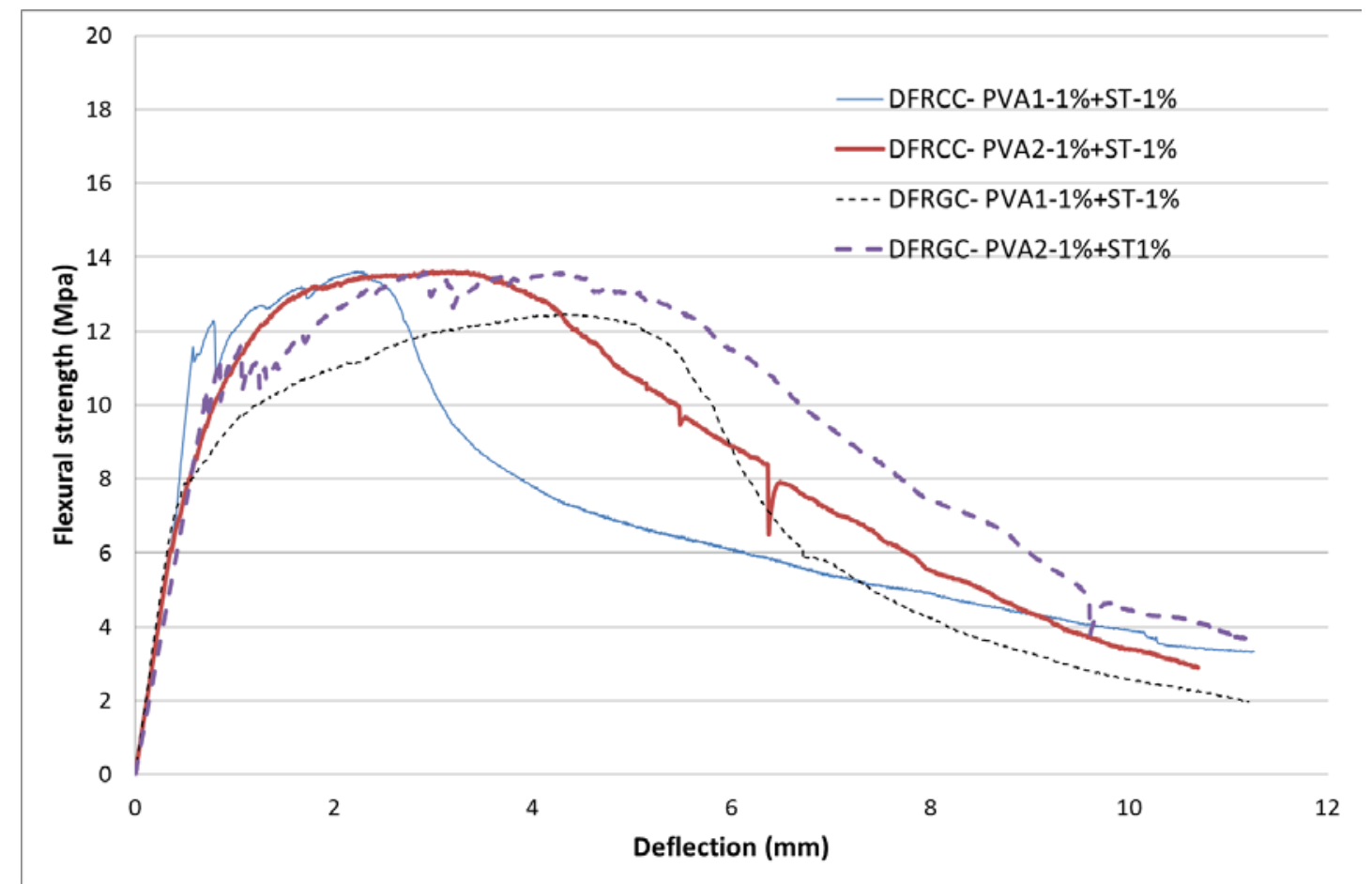

Fig. 9. Deflection hardening behaviour of hybrid fiber reinforced DFRCC and DFRGC in bending containing S/B ratio of 0.5 and maximum sand size of $1.18 \mathrm{~mm}$

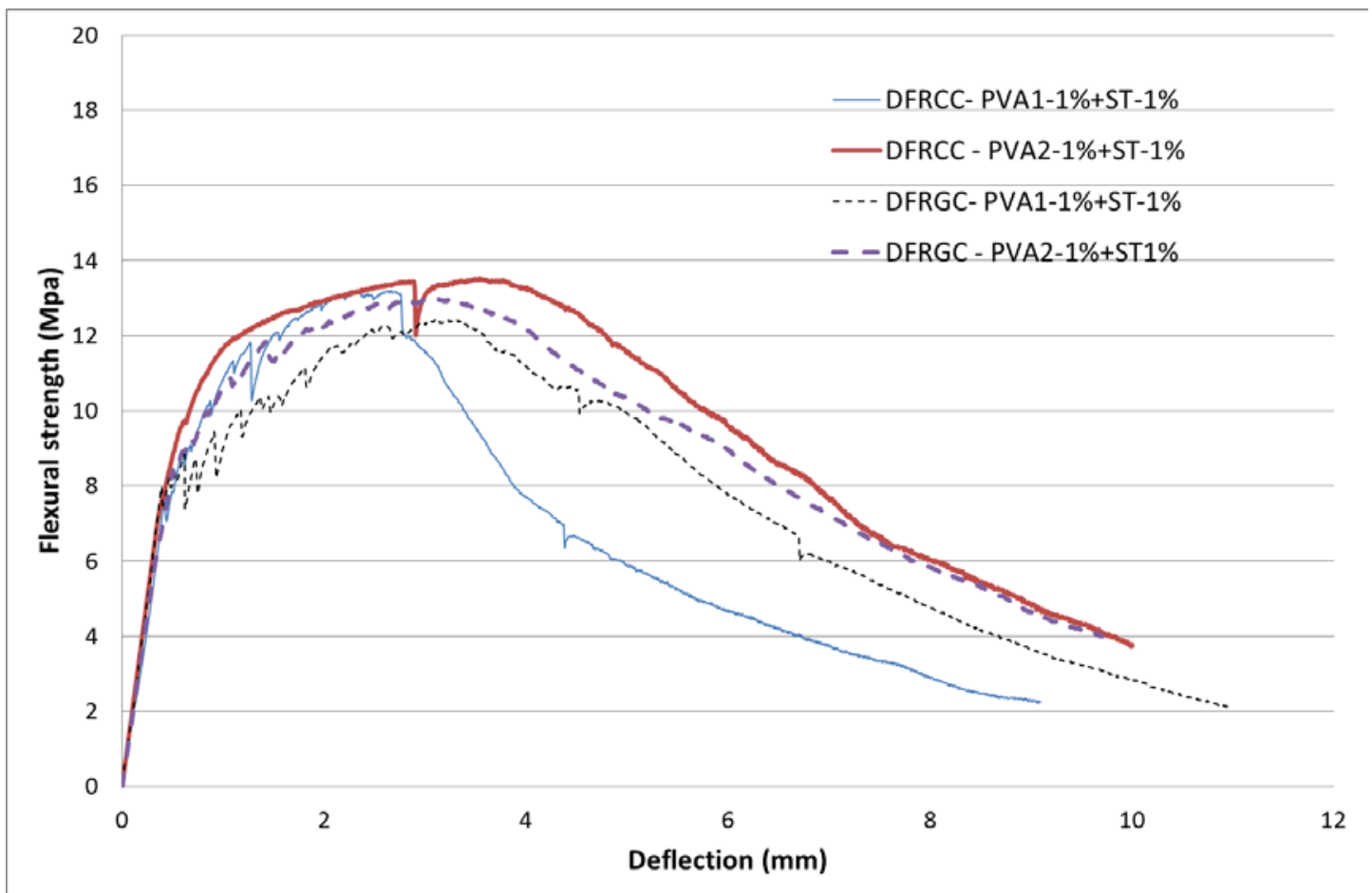

Fig. 10. Deflection hardening behaviour of hybrid fiber reinforced DFRCC and DFRGC in bending containing $\mathrm{S} / \mathrm{B}$ ratio of 0.75 and maximum sand size of $1.18 \mathrm{~mm}$ 

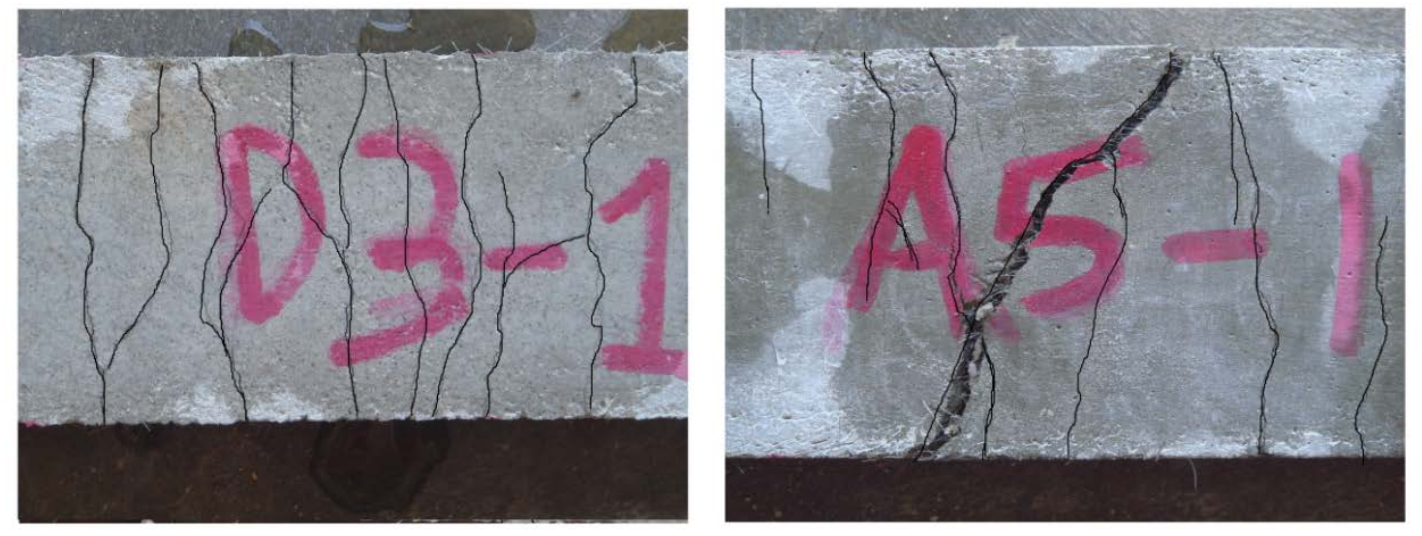

Fig. 11: Multiple Cracking Patterns in DFRCC (Left, PVA-1; right, ST+PVA-1)
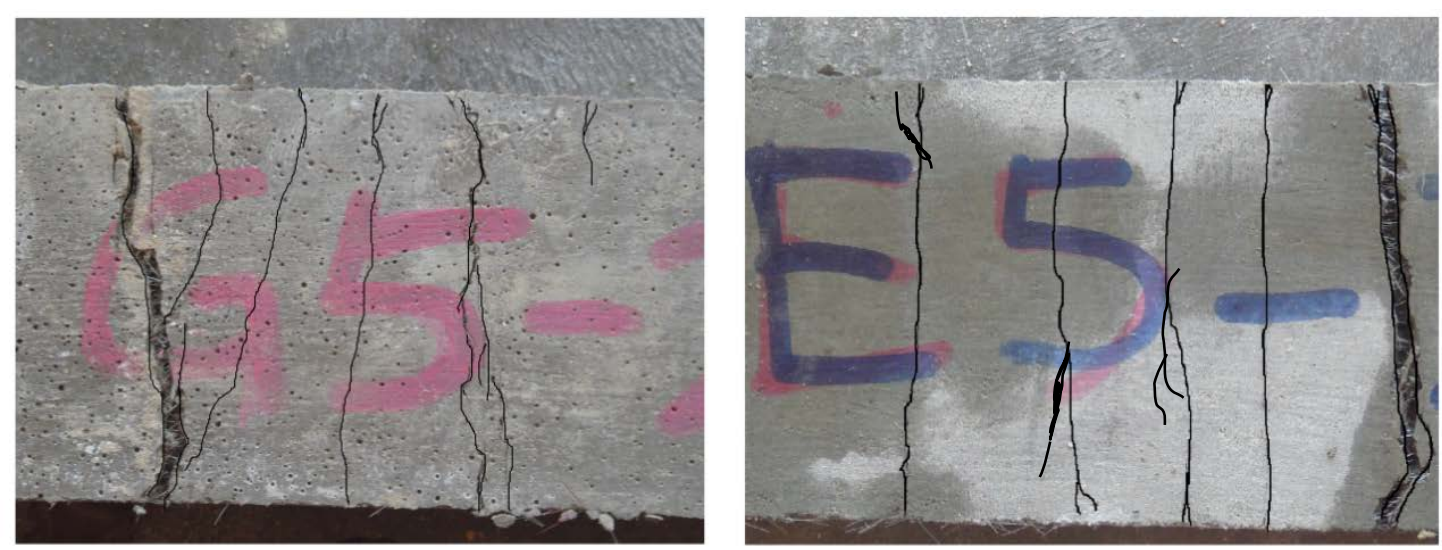

Fig. 12: Multiple Cracking Patterns in DFRGC (Left, PVA-1; right, ST+PVA-1)

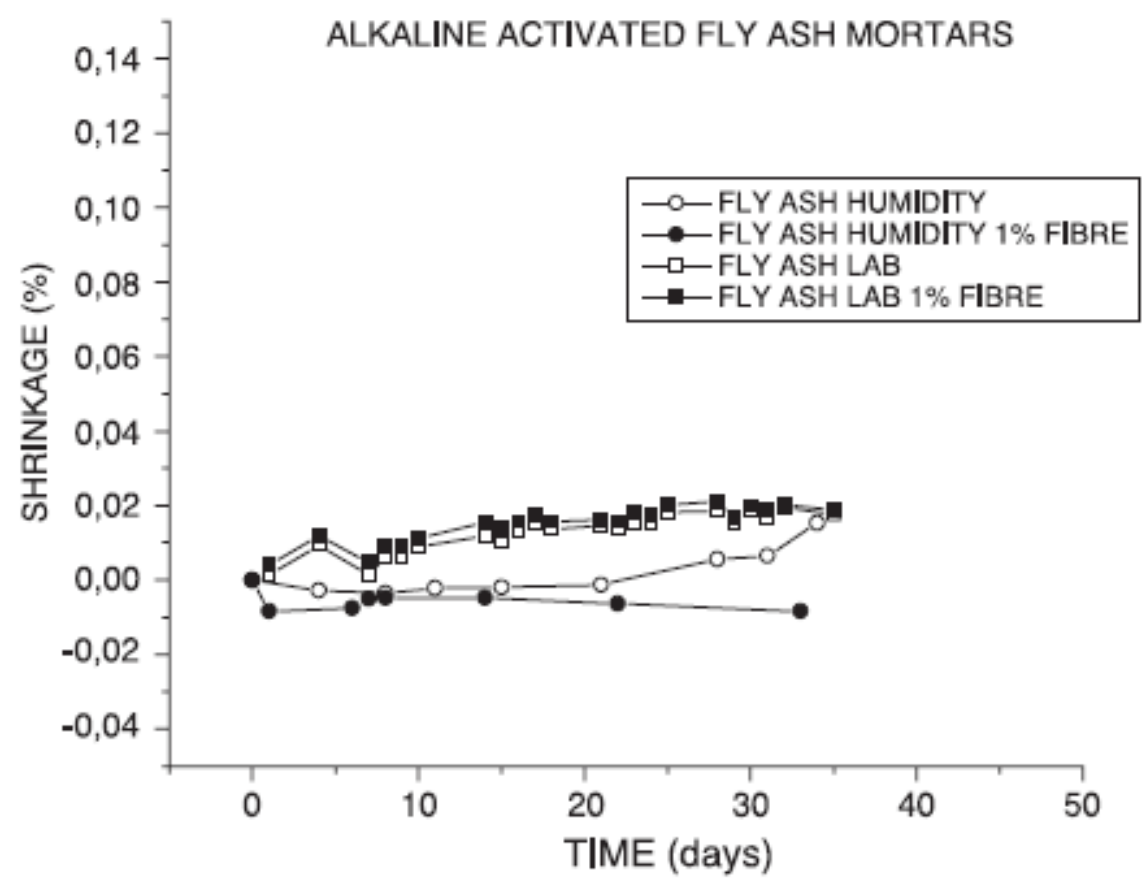

Fig. 13. Shrinkage behaviour of fly ash based FRGC under two different environmental conditions. (adopted from, [13]) 


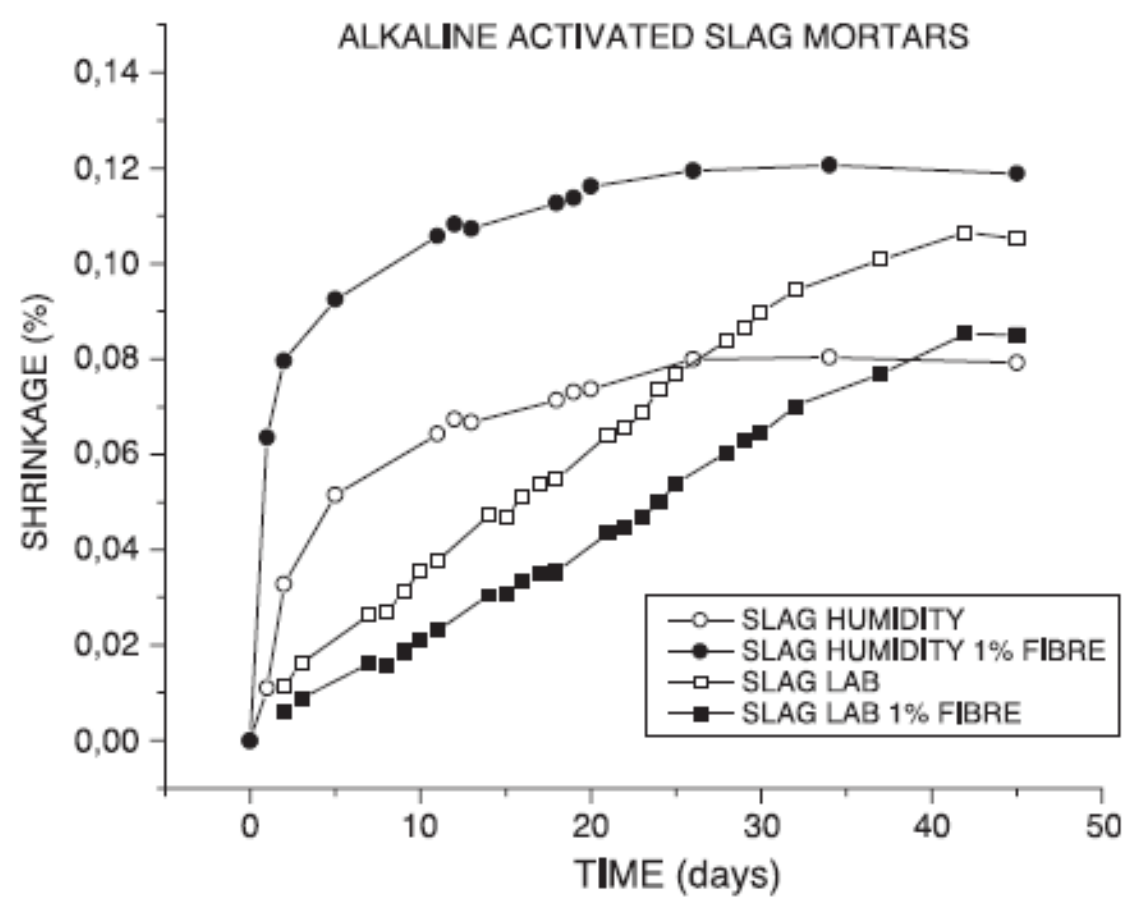

Fig. 14. Shrinkage behaviour of slag based FRGC under two different environmental conditions. (adopted from, [13])

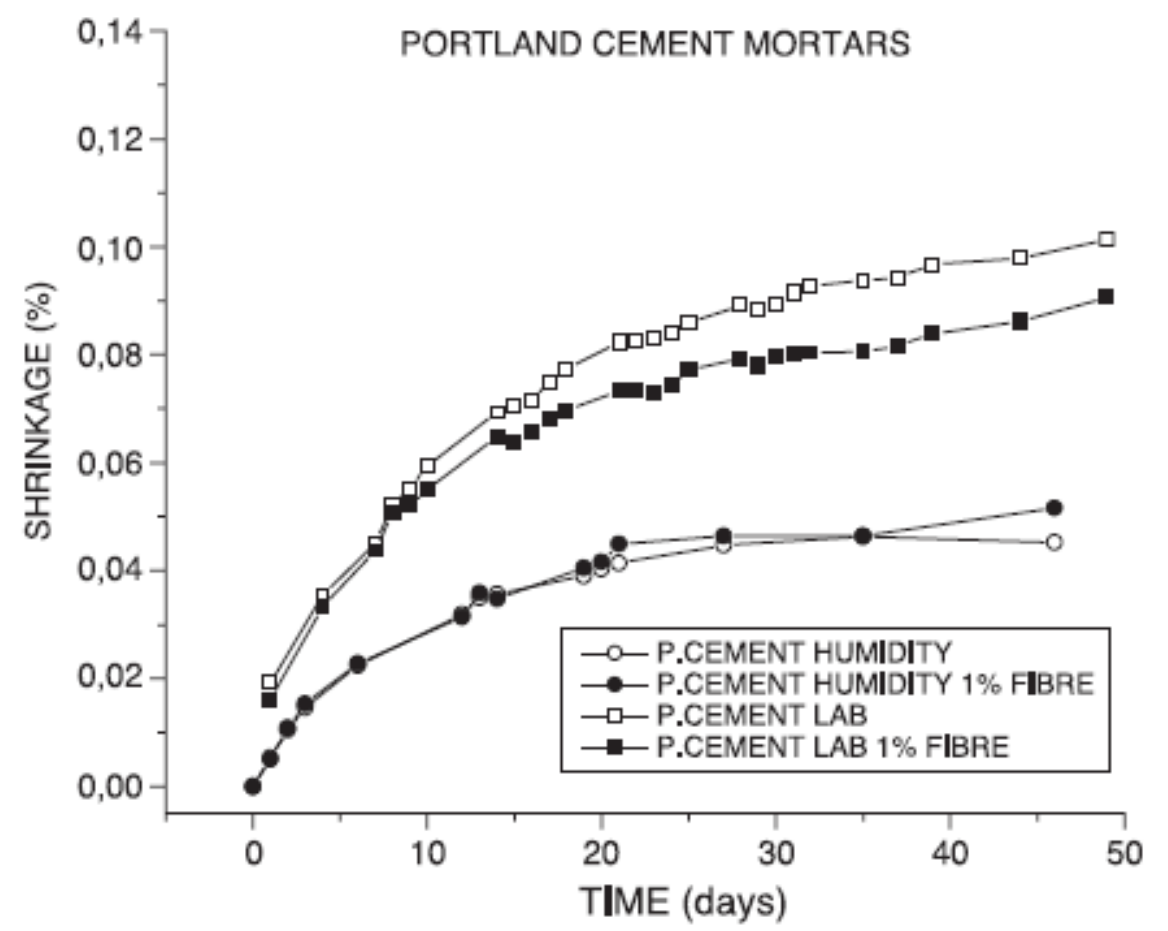

Fig. 15. Shrinkage behaviour of cement based FRCC under two different environmental conditions. (adopted from, [13]) 


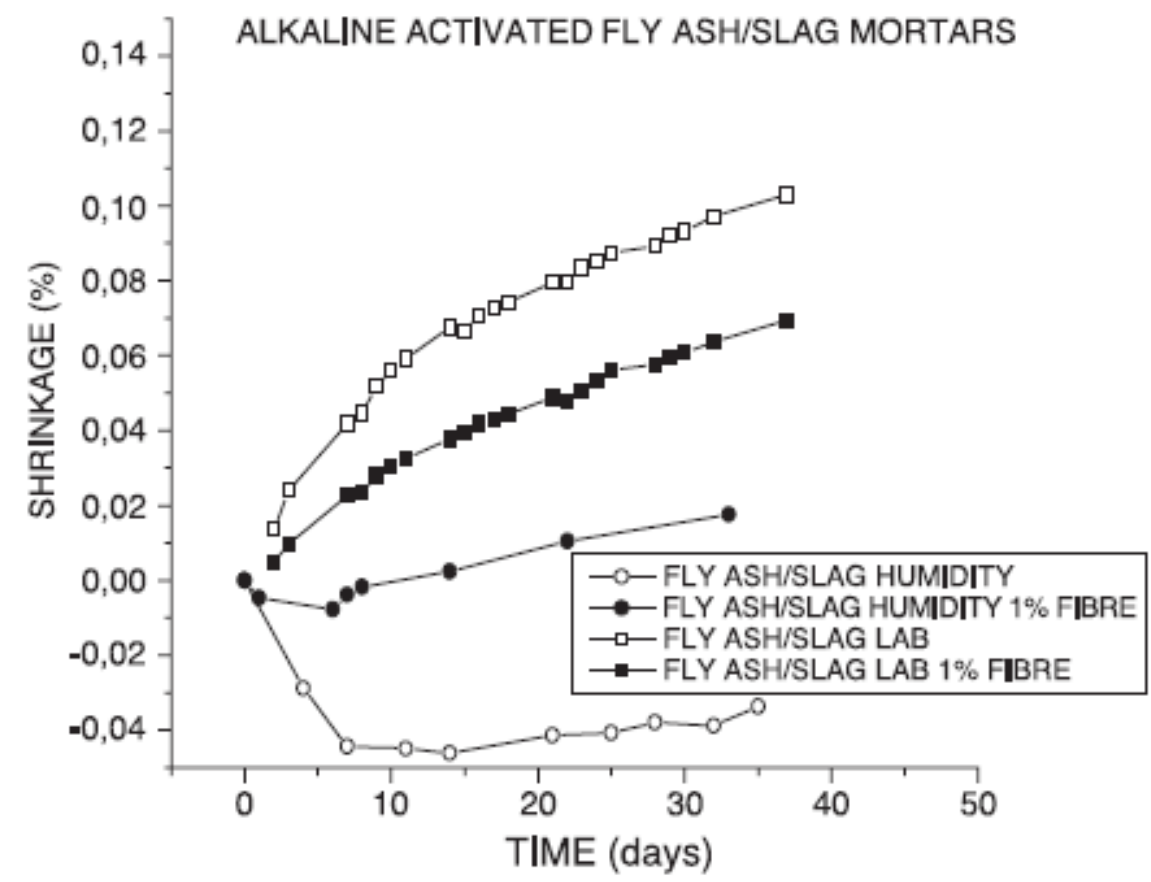

Fig. 16. Shrinkage behaviour of combined fly ash/slag based FRGC under two different environmental conditions. (adopted from, [13])
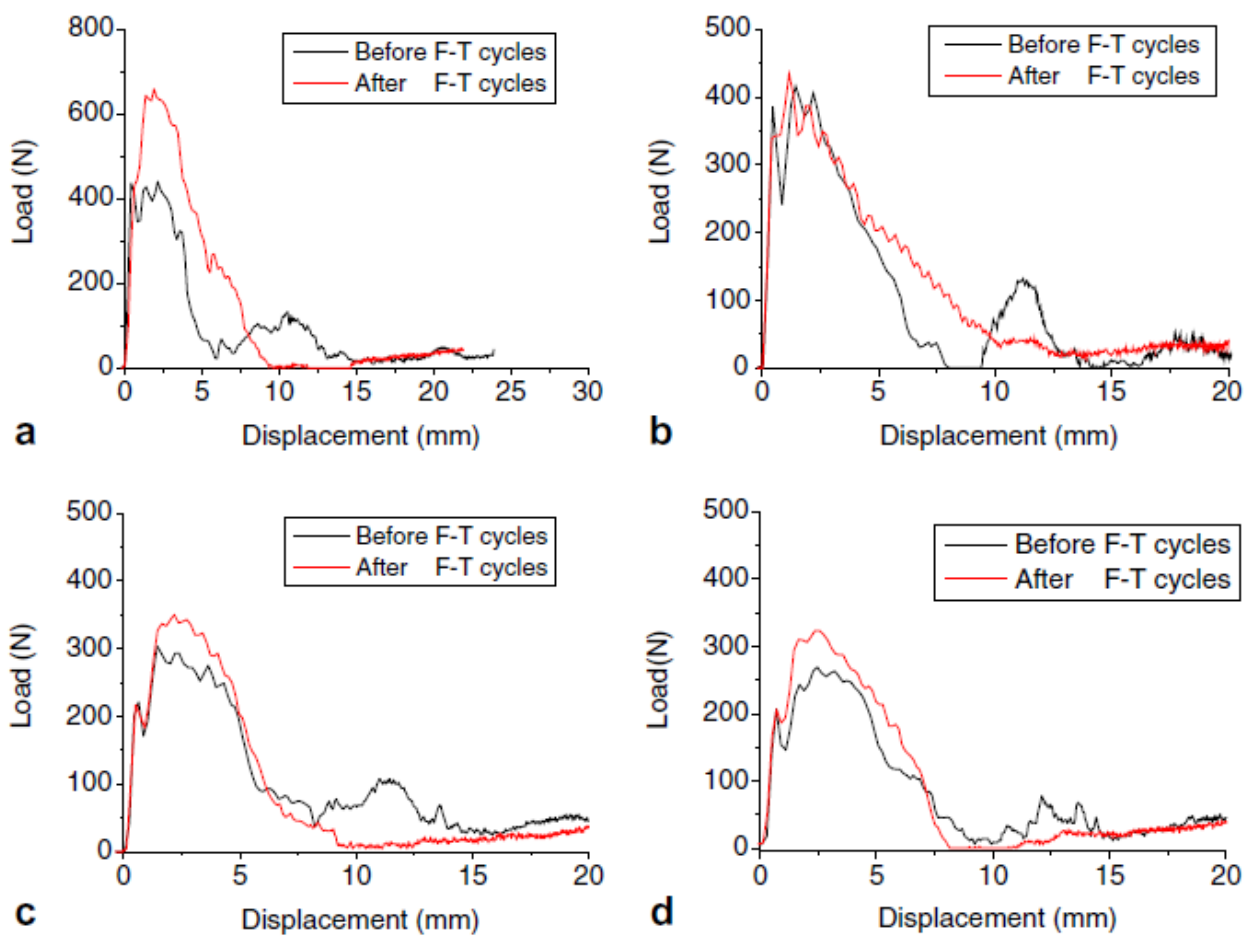

Fig. 17 Impact behaviour of various steel FRGC composites before and after 20 freeze-thaw cycles. (Note figure a is for $0 \%$ fly ash, while figures b, c and d represents $10 \%, 30 \%$ and $50 \%$ fly ash, respectively) (Adopted from [19]) 

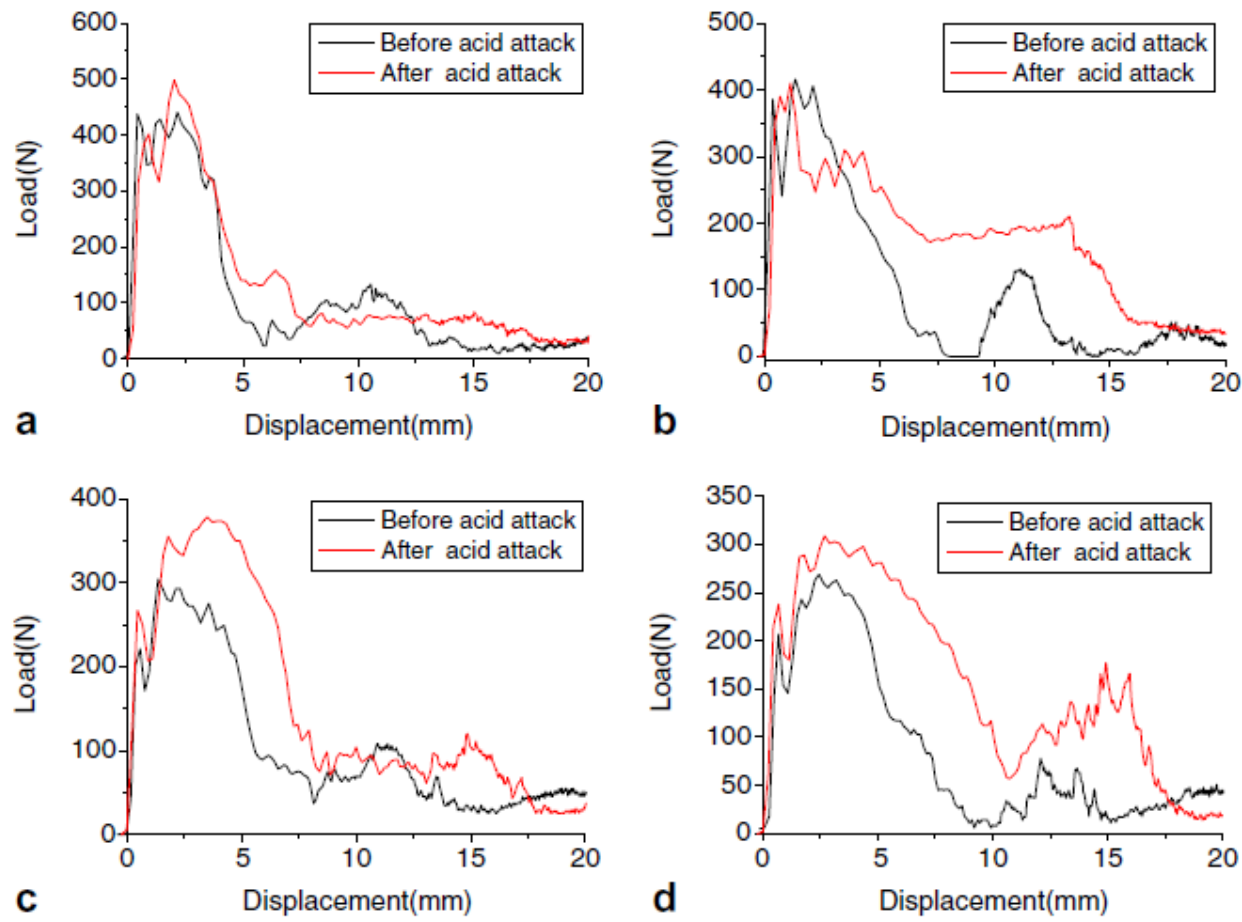

Fig. 18 Impact behaviour of various steel FRGC composites before and after sulphuric acid attack. (Note figure a is for $0 \%$ fly ash, while figures b, c and d represents $10 \%, 30 \%$ and $50 \%$ fly ash, respectively) (Adopted from [19]) 